\title{
Fallopian Tube Cancer pT3b TNM Finding v7
}

National Cancer Institute

\section{Source}

National Cancer Institute. Fallopian Tube CancerpT3b TNM Finding V7. NCI Thesaurus. Code $C 89680$.

Fallopian tube cancer with macroscopic peritoneal metastasis outside the pelvis $2 \mathrm{~cm}$ or less in greatest dimension. (from AJCC 7th Ed.) 